\title{
Effect of SiC whiskers and graphene nanosheets on the mechanical properties of $\mathrm{ZrB}_{2}-\mathrm{SiC}_{\mathrm{w}}$-Graphene ceramic composites
}

\author{
Yumin $A n^{\mathrm{a}, *}$, Xianghong $\mathrm{Xu}{ }^{\mathrm{b}, *}$, Kaixuan Gui ${ }^{\mathrm{a}}$ \\ ${ }^{a}$ National Key Laboratory of Science and Technology on Advanced Composites in Special Environments, Harbin Institute of Technology, Harbin 150001, PR \\ China \\ ${ }^{\mathrm{b}}$ State Key Laboratory of Nonlinear Mechanics (LNM), Institute of Mechanics, Chinese Academy of Sciences, Beijing 100190, PR China
}

\section{A R T I C L E I N F O}

Article history:

Received 14 April 2016

Received in revised form

25 May 2016

Accepted 3 June 2016

Available online 4 June 2016

Keywords:

Graphene nanosheets

$\mathrm{ZrB}_{2}-\mathrm{SiC}_{\mathrm{w}}$

Mechanical properties

\begin{abstract}
A B S T R A C T
Ultrahigh temperature $\mathrm{ZrB}_{2}-\mathrm{SiC}_{\mathrm{w}}$-Graphene ceramic composites are fabricated by hot pressing $\mathrm{ZrB}_{2}-\mathrm{SiC}_{\mathrm{w}}-\mathrm{Graphene}$ oxide powders at $1950{ }^{\circ} \mathrm{C}$ and $30 \mathrm{MPa}$ for $1 \mathrm{~h}$. The microstructures of the composites are characterized by Scanning electron microscopy, Raman spectroscopy and X-ray diffraction. The results show that multilayer graphene nanosheets are achieved by thermal reduction of graphene oxide during sintering process. Compared with monolithic $\mathrm{ZrB}_{2}$ materials, flexural strength and fracture toughness are both improved due to the synergistic effect of $\mathrm{SiC}$ whisker and graphene nanosheets. The toughening mechanisms mainly are the combination of $\mathrm{SiC}$ whisker and graphene nanosheets crack bridging, pulling out.
\end{abstract}

(c) 2016 Elsevier Ltd and Techna Group S.r.l. All rights reserved.

\section{Introduction}

Among various ultrahigh temperature ceramics, zirconium diboride $\left(\mathrm{ZrB}_{2}\right)$ has attracted more and more attention owing to its excellent physical and chemical properties, such as high melting point, high strength, high thermal and electrical conductivity, low density and chemical inertness [1-4]. Generally, the densification of $\mathrm{ZrB}_{2}$ powder requires a high temperature above $2000{ }^{\circ} \mathrm{C}$ at high pressure [5]. To improve the sintering properties of $\mathrm{ZrB}_{2}$, many different kinds of sintering aids are employed to fabricate composites, such as carbon [6], $\mathrm{MoSi}_{2}$ [7], SiC [8,9], et al. Moreover, $\mathrm{ZrB}_{2}$ will be oxidized to $\mathrm{ZrO}_{2}$ and $\mathrm{B}_{2} \mathrm{O}_{3}$ under oxidizing conditions over $800{ }^{\circ} \mathrm{C}[10]$. In the high temperature application environment, it is proved that silicide will be oxidized to form a glassy phase which improves the oxidation resistance of $\mathrm{ZrB}_{2}$ based ceramic composites [11,12]. Furthermore, the enhancement of flexural strength for $\mathrm{ZrB}_{2}-\mathrm{SiC}$ composites is ascribe to that $\mathrm{SiC}$ limits the growth of $\mathrm{ZrB}_{2}$ grain during densification. However, unsatisfactory fracture toughness and poor thermal shock resistance still obstruct their widely application in ultrahigh temperature environment.

Previous investigations have shown that whisker, flake or short fiber gives a promising strategy to improve mechanical properties of ceramic composites [13-15]. In ultrahigh temperature ceramic scopes, $\mathrm{SiC}$ whisker has been used as reinforcement phase due to

\footnotetext{
* Corresponding authors.

E-mail addresses: anyimin@163.com (Y. An), xxh@lnm.imech.ac.cn (X. Xu).
}

the combination of high strength, high elastic modulus and chemical inertness. For example, flexural strength of monolithic $\mathrm{ZrB}_{2}$ ceramic has been significantly improved by the addition of $20 \mathrm{vol} \%$ $\mathrm{SiC}$ whisker $[16,17]$. During the crack propagation process, SiC whisker with high aspect ratio could be pulled out or form crack bridging which resulted in the improvement of fracture toughness. However, some $\mathrm{SiC}$ whisker will be degraded into particles during high temperature sintering process $[18,19]$, which will weaken the reinforcement effect of whisker. So some papers focus on how to achieve dense $\mathrm{ZrB}_{2}-\mathrm{SiC}_{\mathrm{w}}$ composites at lower temperature using the third phase $[20,21]$. Moreover, the combination of various toughening mechanisms induced by the addition of the second and third phase can further enhance fracture toughness of ceramic composites. Recently, graphene nanosheets have been utilized to reinforce $\mathrm{ZrB}_{2}$ based composites [22,23]. The toughening mechanisms mainly are graphene pulling out, graphene crack bridging and three dimensional crack deflection. It is expected that the mechanical properties of ceramic composites will be enhanced by the synergistic effect of $\mathrm{SiC}$ whisker and graphene nanosheets.

Here, homogenously distributed $\mathrm{ZrB}_{2}-\mathrm{SiC}_{\mathrm{w}}$-Graphene oxide (GO) powders are utilized to fabricate $\mathrm{ZrB}_{2}-\mathrm{SiC}_{\mathrm{w}}$-graphene composites in our work. The microstructures and mechanical properties of the novel $\mathrm{ZrB}_{2}-\mathrm{SiC}_{\mathrm{w}}-\mathrm{Graphene}$ ceramic composites are investigated and discussed in detail. The results show that flexural strength and fracture toughness are both improved compared with monolithic $\mathrm{ZrB}_{2}$ materials. The toughening mechanisms are analyzed based on microstructures. Our work offers a promising way to improve mechanical properties of ceramic composites. 


\section{Experimental}

Commercial raw materials were utilized in the fabrication process of ceramic composites. The mean particle size of $\mathrm{ZrB}_{2}(99 \%$, Northwest Institute for Non-ferrous Metal Research, China) was $\sim 2 \mu \mathrm{m}$. The SiC whisker (98\%, Alfa Aesar, USA) had a diameter of $0.5-2.5 \mu \mathrm{m}$ and a length of 5-50 $\mu \mathrm{m}$. Graphite flakes (> 99\%, Alfa Aesar, USA) with 325 mesh were used to prepare GO through modified Hummer's method. The fabrication process could be found in a previous work [22]. After GO solution sonication for $2 \mathrm{~h}$, $\mathrm{ZrB}_{2}$ plus 20 vol\% $\mathrm{SiC}_{\mathrm{w}}$ were added to the dispersion. Then the ceramic-GO slurry was ball milled with $\mathrm{ZrO}_{2}$ balls for $8 \mathrm{~h}$ at the speed of $280 \mathrm{rpm}$. After that, rotary evaporation was employed to dry the homogeneously mixed slurry at $60{ }^{\circ} \mathrm{C}$ to minimize segregation. Uniformly mixed $\mathrm{ZrB}_{2}-\mathrm{SiC}_{\mathrm{w}}-\mathrm{GO}$ powder mixture was hot pressing at $1950{ }^{\circ} \mathrm{C}$ for $1 \mathrm{~h}$ in $\mathrm{Ar}$ atmosphere. A uniaxial load of $30 \mathrm{MPa}$ and heating rate about $15^{\circ} \mathrm{C} / \mathrm{min}$ were used in the sintering process.

Relative density of the ceramic composites was measured by Archimedes method. Three points bending method was utilized to test flexural strength. The size of test bars was $3 \mathrm{~mm} \times 4 \mathrm{~mm} \times 36 \mathrm{~mm}$. The span was $30 \mathrm{~mm}$ and a crosshead speed of $0.5 \mathrm{~mm} / \mathrm{min}$ was employed. Fracture toughness was determined by single edge notched beam test on $2 \mathrm{~mm} \times 4 \mathrm{~mm} \times 22 \mathrm{~mm}$ bars using $16 \mathrm{~mm}$ span with a crosshead speed of $0.05 \mathrm{~mm} / \mathrm{min}$. All mechanical properties were the average value of five specimens. The test bars were all cut on the surface perpendicular to hot pressing direction. The microstructures of the novel $\mathrm{ZrB}_{2}-\mathrm{SiC}_{\mathrm{w}}$-Graphene ceramic composites were characterized using X-ray diffraction (Rigaku, Dmax-rb, Cuk $\alpha$ $1.5425 \AA$ A), Micro-Raman spectroscopy (REMSHAW Invia, laser wavelength: $633 \mathrm{~nm}$ ) and Scanning electron microscopy (SEM, FEI Sirion, Holland).

\section{Results and discussion}

A polished surface of $\mathrm{ZrB}_{2}-\mathrm{SiC}_{\mathrm{w}}$-Graphene ceramic composite was shown in Fig. 1a. It was clearly found that acicular $\mathrm{SiC}_{\mathrm{w}}$ was homogenously distributed in the composite. Moreover, there were some dark particle phases distributed among the matrix. In the hot pressing process, some SiC whiskers were unavoidably degraded into particles, which was also discussed in other studies [18,19]. On the polished surface, there was no graphene found due to its

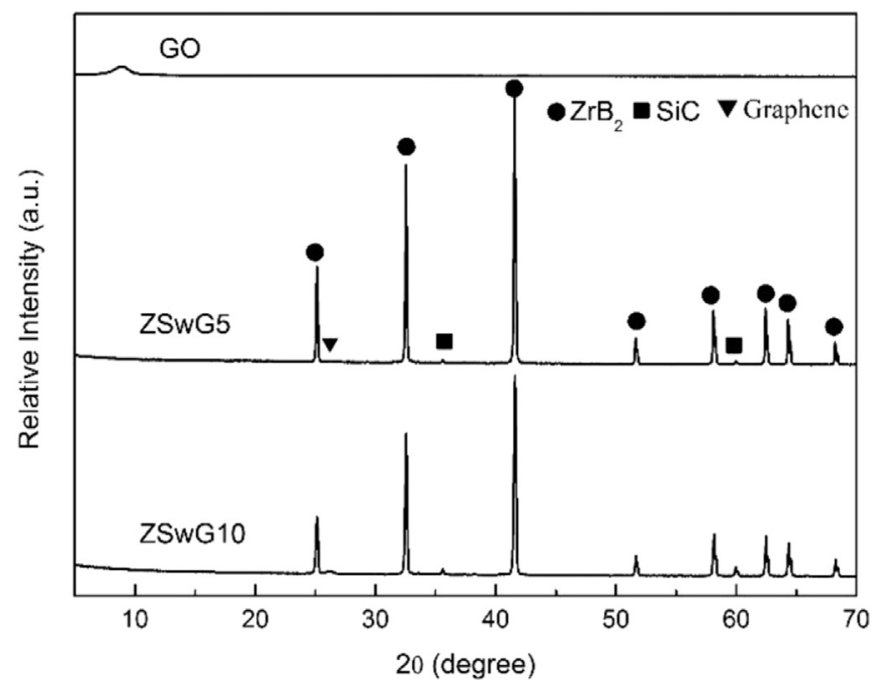

Fig. 2. X-Ray diffraction of $\mathrm{ZrB}_{2}-\mathrm{SiC}_{\mathrm{w}}$-Graphene ceramic composites and GO. Circle dots represent $\mathrm{ZrB}_{2}$, square dots stand for $\mathrm{SiC}_{\mathrm{w}}$, and triangle dots was assigned to graphene.

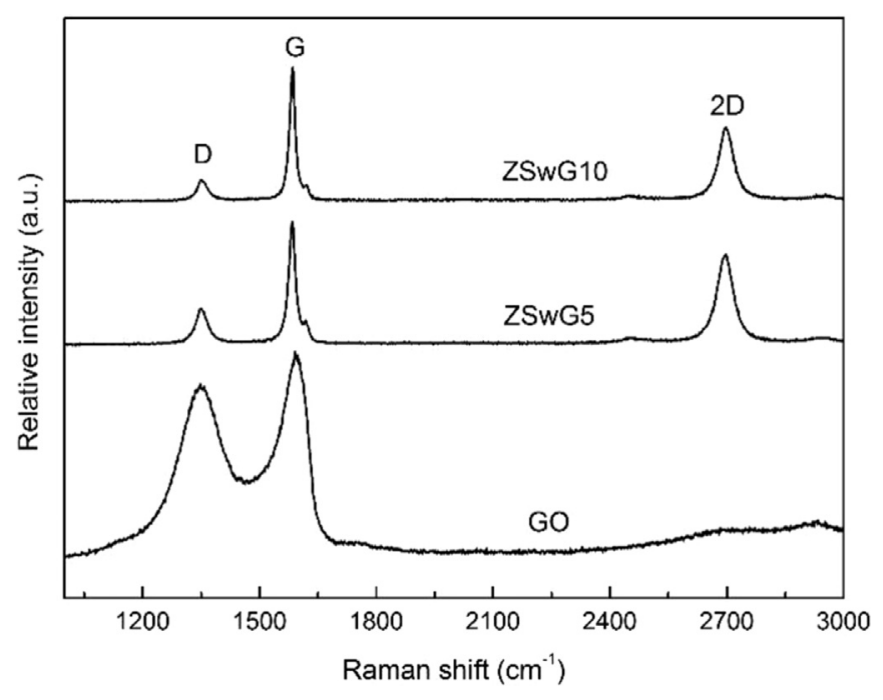

Fig. 3. Raman spectrum of $\mathrm{ZrB}_{2}-\mathrm{SiC}_{\mathrm{w}}$-Graphene ceramic composites and GO.
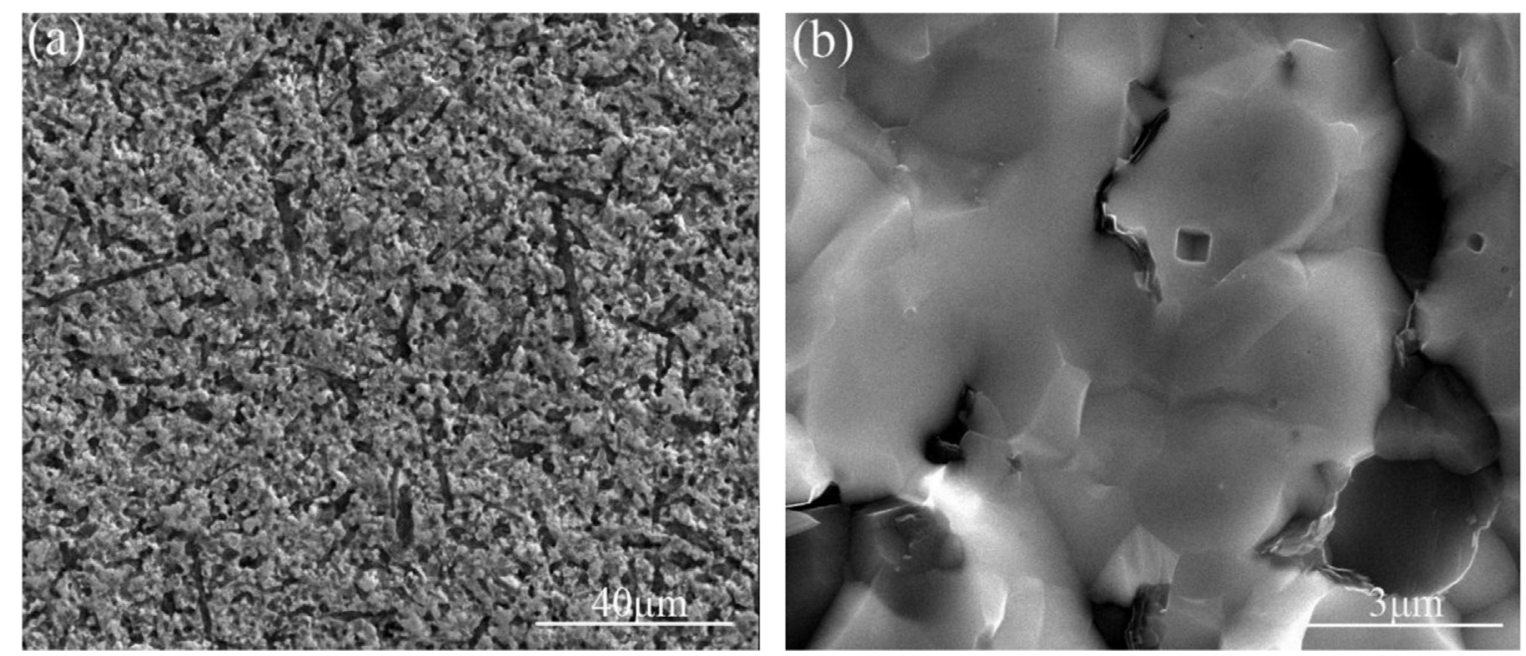

Fig. 1. SEM images of a polished surface (a) and fracture surface (b) of $\mathrm{ZrB}_{2}-\mathrm{SiC}_{\mathrm{w}}-\mathrm{Graphene} \mathrm{ceramic} \mathrm{composites.}$ 
Table 1

Average $\mathrm{D}, \mathrm{G}$ and 2D Raman spectra properties of $\mathrm{ZrB}_{2}-\mathrm{SiC}_{\mathrm{w}}-\mathrm{Graphene}$ composites and GO.

\begin{tabular}{llllll}
\hline Materials & $\mathrm{D}$ & $\mathrm{G}$ & $2 \mathrm{D}$ & $\mathrm{I}_{\mathrm{D}} / \mathrm{I}_{\mathrm{G}}$ & $\mathrm{I}_{2 \mathrm{D}} / \mathrm{I}_{\mathrm{G}}$ \\
\hline GO & 1347.8 & 1591.2 & - & 0.84 & - \\
ZSwG5 & 1349.3 & 1583.1 & 2696.5 & 0.31 & 0.74 \\
ZSwG10 & 1351.1 & 1584.7 & 2697.9 & 0.16 & 0.55 \\
\hline
\end{tabular}

Table 2

Flexural strength, fracture toughness and relative density of $\mathrm{ZrB}_{2}-\mathrm{SiC}_{\mathrm{w}}-\mathrm{Graphene}$ composites.

\begin{tabular}{llll}
\hline Materials & $\begin{array}{l}\text { Flexural strength } \\
(\mathrm{MPa})\end{array}$ & $\begin{array}{l}\text { Fracture toughness } \\
\left(\mathrm{MPa} \mathrm{m}^{0.5}\right)\end{array}$ & $\begin{array}{l}\text { Relative density } \\
(\%)\end{array}$ \\
\hline ZSwG5 & $764 \pm 38$ & $6.6 \pm 0.3$ & 98.5 \\
ZSwG10 & $681 \pm 55$ & $5.8 \pm 0.2$ & 99.3 \\
\hline
\end{tabular}

low magnification. However, graphene nanosheets appeared between $\mathrm{ZrB}_{2}$ particles and $\mathrm{SiC}_{\mathrm{w}}$, depicted in fracture surface of the ceramic composite (Fig. 1b).

Here, XRD and Raman spectroscopy were employed to analyze the effect of in situ thermal reduction of GO in the ceramic composites. The results were shown in Figs. 2 and 3, respectively. During oxidize process, strong oxidant intercalated into graphite layers and lots of oxygen containing groups were formed on the surface of graphite flakes. After sonication, the thickness of graphite oxide changed to nanoscale, forming GO. The XRD peak of GO was located approximately $9^{\circ}$, revealing high quality GO was achieved. In fabrication process of the ceramic composites, five (ZSwG5) and ten (ZSwG10) volumes of GO were used. Typical $\mathrm{ZrB}_{2}$ peaks and $\beta$-SiC peaks were clearly depicted in XRD patterns for ZSwG5 composite. There was no peak found for graphene nanosheets, which might owe to the small quantities of graphene in the composites. However, the disappear of peaks located approximately $9^{\circ}$ revealed that most of the oxygen containing functional groups in GO were removed during the high temperature sintering process [24] and one small peak located at $26^{\circ}$ appeared in XRD spectrum of ZSwG10 ceramic composites, which indicated that GO was thermally reduced to graphene nanosheets. As reported previously, the strong $(002)$ reflection $\left(2 \theta \sim 26^{\circ}\right)$ was a result of wave interference between scattering by different graphene layers [25-27].

In Fig. 3, only the typical D peak $\left(1347.8 \mathrm{~cm}^{-1}\right)$ and $G$ peak $\left(1591.2 \mathrm{~cm}^{-1}\right)$ were found for original GO. After high temperature sintering process, D peak shifted right $2 \mathrm{~cm}^{-1}$ and $G$ peak shifted left about $8 \mathrm{~cm}^{-1}$ for ZSwG5 ceramic composites. Furthermore, one typical 2D peak of carbonaceous materials appeared at $2696.5 \mathrm{~cm}^{-1}$ except $D$ peak and $G$ peak, which indicated thermal reduction of GO during sintering process exhibited double resonance mode of graphene. Typical D peak $\left(1351.1 \mathrm{~cm}^{-1}\right), \mathrm{G}$ peak $\left(1584.7 \mathrm{~cm}^{-1}\right)$ and 2D peak $\left(2697.9 \mathrm{~cm}^{-1}\right)$ were easily observed in Raman spectrum for ZSwG10 ceramic composites. To further analyze the thermal reduction effect of GO and graphene structures in the ceramic composites, two intensity ratio parameters $\left(\mathrm{I}_{\mathrm{D}} / \mathrm{I}_{\mathrm{G}}\right.$ and $\left.\mathrm{I}_{2 \mathrm{D}} / \mathrm{I}_{\mathrm{G}}\right)$ of these three peaks for carbonaceous materials were calculated. Compared with original $\mathrm{GO}$, the average $\mathrm{I}_{\mathrm{D}} / \mathrm{I}_{\mathrm{G}}$ of ZSwG5 decreased from 0.84 to 0.31 . Graphitic domain La could be calculated using the expression of $2.4 \mathrm{e}^{-10^{*}} \lambda_{\text {laser }}{ }^{4 *}\left(\mathrm{I}_{\mathrm{D}} / \mathrm{I}_{\mathrm{G}}\right)^{-1}\left(\lambda_{\text {laser }}\right.$ represents the wave length of laser) [28]. Then graphitic domain of graphene structures in ZSwG5 ceramic composites notably increased after the thermal reduction process. For ZSwG10 ceramic composites, the average crystallite size La of graphene structures in the composites increased significantly from $45.8 \mathrm{~nm}$ to $240.8 \mathrm{~nm}$. These findings were consistent with the results of XRD. In early reports, there was strong relationship between $\mathrm{I}_{2 \mathrm{D}} / \mathrm{I}_{\mathrm{G}}$ and layer number of graphene. For monolayer or bilayer graphene, $\mathrm{I}_{2 \mathrm{D}} / \mathrm{I}_{\mathrm{G}}$ was more than 1 with single and sharp $2 \mathrm{D}$ peaks. As the layer number of graphene increased, $\mathrm{I}_{2 \mathrm{D}} / \mathrm{I}_{\mathrm{G}}$ decreased from 1 to 0.5 [29]. For ZSwG5 and ZSwG10 composites, the calculated value $\mathrm{I}_{2 \mathrm{D}} / \mathrm{I}_{\mathrm{G}}$ was in the range of $0.5-1$ which proved that multilayer graphene structure existed in the composites after sintering process. It is worth mentioning that $\mathrm{I}_{2 \mathrm{D}} / \mathrm{I}_{\mathrm{G}}$ of ZSwG5 was a little higher than that of ZSwG10, revealing the thickness of graphene nanosheets in ZSwG5 was smaller. The detail data of Raman spectra was listed in Table 1.

Here, almost fully dense composites were achieved after sintering process. The relative densities of ZSwG5 and ZSwG10 composites were 98.5\% and 99.3\%, respectively. Mechanical properties of the ceramic composites under investigation were listed in Table 2. Compared with $270-480 \mathrm{MPa}$ of pure $\mathrm{ZrB}_{2}$ ceramic [30], the strength of ZSwG5 and ZSwG10 ceramic composites were both enhanced by the addition of $\mathrm{SiC}_{\mathrm{w}}$ and graphene nanosheets. With the volume fraction of graphene increased, the strength decreased from $764 \mathrm{MPa}$ (ZSwG5) to $681 \mathrm{MPa}$ (ZSwG10). Additionally, the flexural strength of $\mathrm{ZrB}_{2}-\mathrm{SiC}_{\mathrm{w}}$-graphene composites was also higher than the reported results for $\mathrm{ZrB}_{2}-\mathrm{SiC}_{\mathrm{w}}(660 \mathrm{MPa})$ [18] and $\mathrm{ZrB}_{2}$-graphene (316 MPa) [23] composites. The measured fracture toughness of the novel ceramic composite were $6.6 \mathrm{MPa} \mathrm{m}{ }^{0.5}$ (ZSwG5) and $5.8 \mathrm{MPa} \mathrm{m}^{0.5}$ (ZSwG10), which were also higher than
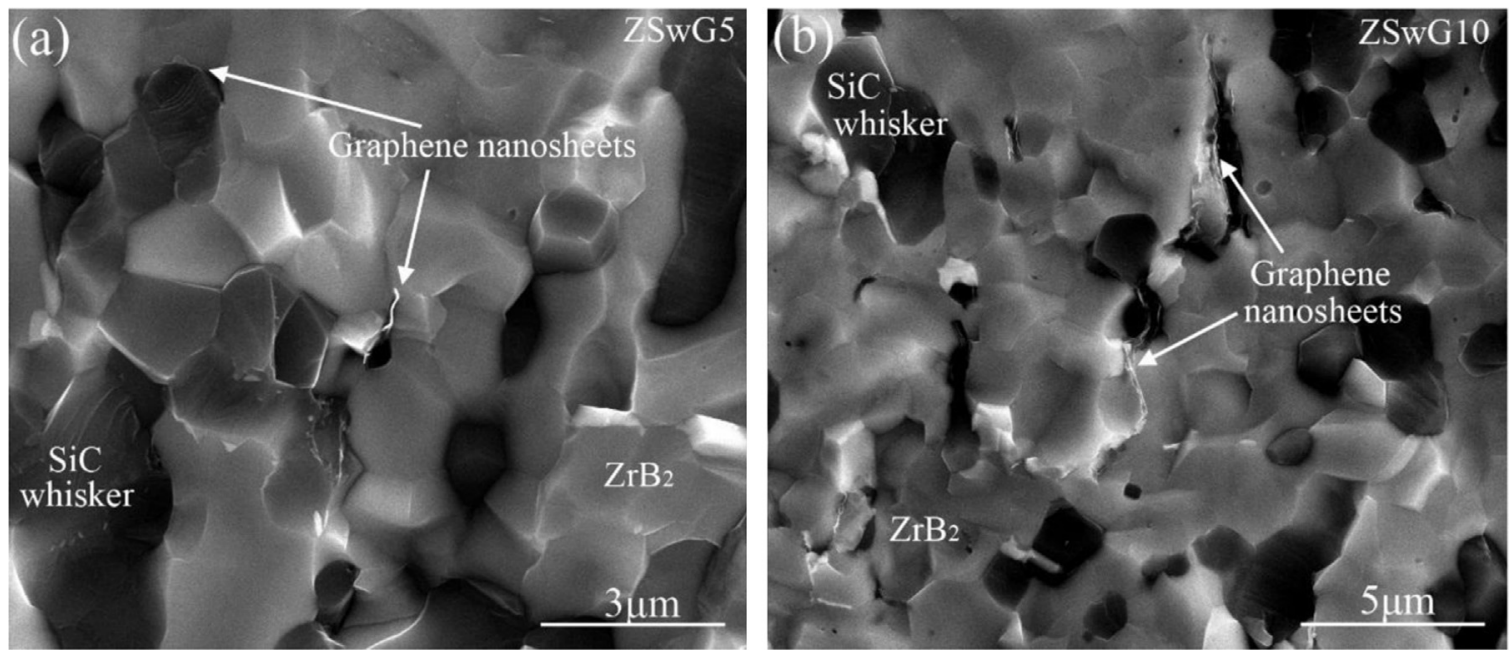

Fig. 4. SEM images of fracture surface of $\mathrm{ZrB}_{2}-\mathrm{SiC}_{\mathrm{w}}$-Graphene ceramic composites with 5 vol\% (a) and $10 \mathrm{vol} \%$ (b) GO. 

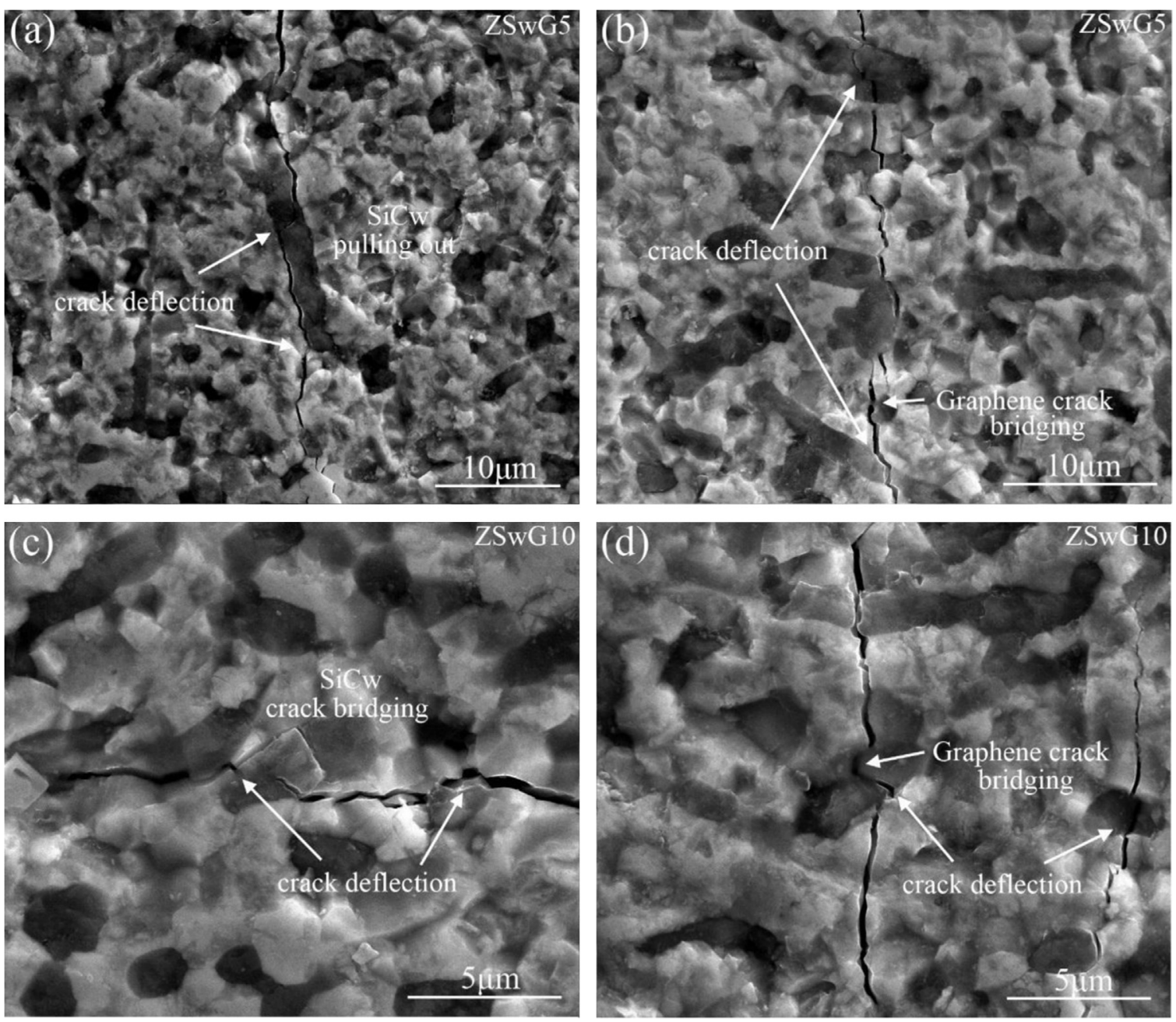

Fig. 5. Typical indentation crack propagates in $\mathrm{ZrB}_{2}-\mathrm{SiC}_{\mathrm{w}}$-Graphene ceramic composites.

monolithic $\mathrm{ZrB}_{2}$ ceramic $\left(2.3-3.5 \mathrm{MPa} \mathrm{m}^{0.5}\right), \quad \mathrm{ZrB}_{2}$-graphene $\left(2.77 \mathrm{MPa} \mathrm{m}^{0.5}\right)$ and $\mathrm{ZrB}_{2}-\mathrm{SiC}_{\mathrm{w}}\left(5.3 \mathrm{MPa} \mathrm{m}^{0.5}\right)$ composites. In these composites, the particle sizes of $\mathrm{ZrB}_{2}, \mathrm{SiC}_{\mathrm{w}}$ and graphene were almost the same as ours. The volume ratio of $\mathrm{SiC}_{\mathrm{w}}$ and graphene was $20 \mathrm{vol} \%$ and $6 \mathrm{vol} \%$, respectively. With the volume fraction of graphene nanosheets increased, the decrease of flexural strength and fracture toughness might due to the agglomeration of graphene nanosheets during the material fabrication process.

The microstructures of the fracture surface (Fig. 4) and indentation crack propagation path (Fig. 5) were utilized to illustrate the synergistic effect of $\mathrm{SiC}_{\mathrm{w}}$ and graphene nanosheets on mechanical properties. In Fig. $4 \mathrm{a}$ and b, graphene nanosheets were found between adjacent $\mathrm{ZrB}_{2}$ particles and $\mathrm{SiC}_{\mathrm{w}}$. The thickness of graphene nanosheets in ZSwG10 was thicker than ZSwG5 composites, revealing that some graphene nanosheets agglomerated together during the fabrication process. It was consistent with the results illustrated in Raman spectrum. Moreover, both graphene nanosheets and $\mathrm{SiC}_{\mathrm{w}}$ pulling out could be found in the fracture surface. When crack propagated in ZSwG5 composites, crack deflection was found after $\mathrm{SiC}_{\mathrm{w}} \cdot \mathrm{SiC}_{\mathrm{w}}$ pulling out appeared in the crack path. Furthermore, graphene nanosheets crack bridging was also found in the indentation crack path shown in Fig. 5b. For ZSwG10 composites, both $\mathrm{SiC}_{\mathrm{w}}$ and graphene nanosheets crack bridging were easily observed after the crack propagated through the composites. It was easily found that crack deflection appeared after the $\mathrm{SiC}_{\mathrm{w}}$ and graphene crack bridging. The synergistic effect of $\mathrm{SiC}_{\mathrm{w}}$ pulling out, crack bridging and graphene nanosheets crack bridging during material failure resulted in the improvement of mechanical properties for $\mathrm{ZrB}_{2}-\mathrm{SiC}_{\mathrm{w}}-\mathrm{Graphene}$ ceramic composites.

\section{Conclusion}

In summary, $\mathrm{ZrB}_{2}-\mathrm{SiC}_{\mathrm{w}}$-Graphene ceramic composites were fabricated by hot pressing $\mathrm{ZrB}_{2}-\mathrm{SiC}_{\mathrm{w}}$-Graphene oxide powders. XRD patterns and Raman spectrum showed that GO was thermally reduced to multilayer graphene nanosheets during sintering process. Flexural strength and fracture toughness were both improved by the addition of SiC whisker and graphene nanosheets. However, the mechanical properties weakened when the volume fraction of GO increased from $5 \%$ to $10 \%$, which may owe to the agglomeration of graphene nanosheets in the composites. The synergistic effect of $\mathrm{SiC}_{\mathrm{w}}$ pulling out, crack bridging and graphene nanosheets crack bridging enhanced fracture toughness of $\mathrm{ZrB}_{2}-\mathrm{SiC}_{\mathrm{w}^{-}}$ Graphene ceramic composites.

\section{Acknowledgement}

The authors are grateful for the support from National Natural Science Foundation of China (No. 11272313). 


\section{References}

[1] S.M. Zhu, W.G. Fahrenholtz, G.E. Hilmas, S.C. Zhang, Pressureless sintering of zirconium diboride using boron carbide and carbon additions, J. Am. Ceram. Soc. 90 (2007) 3660-3663.

[2] Y.M. An, J.C. Han, W.B. Han, G.D. Zhao, B.S. Xu, K.F. Jin, X.H. Zhang, Chemica vapor deposition synthesis carbon nanosheet-coated zirconium diboride particles for improved fracture toughness, J. Am. Ceram. Soc. 1 (2016) 1-7.

[3] R.J. He, X.H. Zhang, P. Hu, C. Liu, W.B. Han, Aqueous gelcasting of $\mathrm{ZrB}_{2}$-SiC ultra high temperature ceramics, Ceram. Int. 38 (2012) 5411-5418.

[4] F. Monteverde, A. Bellosi, Effect of the addition of silicon nitride on sintering behavior and microstructure of zirconium diboride, Scr. Mater. 46 (2002) 223-228.

[5] D. Sciti, S. Guicciardi, A. Bellosi, Properties of a pressureless-sintered $\mathrm{ZrB}_{2}-\mathrm{MoSi}_{2}$ ceramic composite, J. Am. Ceram. Soc. 89 (2006) 2320-2322.

[6] S.M. Zhu, W.G. Fahrenholtz, G.E. Hilmas, S.C. Zhang, Pressureless sintering of carbon-coated zirconium diboride powders, Mat. Sci. Eng. A 459 (2007) 167-171.

[7] D. Sciti, M. Brach, A. Bellosi, Long-term oxidation behavior and mechanical strength degradation of a pressurelessly sintered $\mathrm{ZrB}_{2}-\mathrm{MoSi}_{2}$ ceramic, Scr. Mater. 53 (2005) 1297-1302.

[8] Q. Liu, W.B. Han, X.H. Zhang, S. Wang, J.C. Han, Microstructure and mechanical properties of $\mathrm{ZrB}_{2}$-SiC composites, Mater. Lett. 63 (2009) 1323-1325.

[9] J.W. Zimmermann, G.E. Hilmas, W.G. Fahrenholtz, Thermal shock resistance of $\mathrm{ZrB}_{2}$ and $\mathrm{ZrB}_{2}-30 \%$ SiC, Mater. Chem. Phys. 112 (2008) 140-145.

[10] S.B. Zhou, W.J. Li, P. Hu, C.Q. Hong, L. Weng, Ablation behavior of $\mathrm{ZrB}_{2}-\mathrm{SiC}-\mathrm{ZrO}_{2}$ ceramic composites by means of the oxyacetylene torch, Corros. Sci. 51 (2009) 2071-2079.

[11] X.Y. Li, X.H. Zhang, J.C. Han, C.Q. Hong, W.B. Han, A technique for ultrahigh temperature oxidation studies of $\mathrm{ZrB}_{2}$-SiC, Mater. Lett. 62 (2008) 2848-2850.

[12] P. Hu, G.L. Wang, Z. Wang, Oxidation mechanism and resistance of $\mathrm{ZrB}_{2}-\mathrm{SiC}$ composites, Corros. Sci. 51 (2009) 2724-2732.

[13] J. Lin, X.H. Zhang, H.J. Cao, H. Jin, W.B. Han, R-curve behavior, mechanical properties and microstructure of sintered $\mathrm{ZrB}_{2}-\mathrm{SiC}_{\mathrm{p}}-\mathrm{ZrO}_{2 \mathrm{f}}$ ceramics, J. Eur Ceram. Soc. 32 (2012) 1743-1749.

[14] F.Y. Yang, X.H. Zhang, J.C. Han, S.Y. Du, Characterization of hot-pressed short carbon fiber reinforced $\mathrm{ZrB}_{2}-\mathrm{SiC}$ ultra-high temperature ceramic composites, J. Alloy. Compd. 472 (2009) 395-399.

[15] S.B. Zhou, Z. Wang, W. Zhang, Effect of graphite flake orientation on microstructure and mechanical properties of $\mathrm{ZrB}_{2}-\mathrm{SiC}$-graphite composite, J. Alloy. Compd. 485 (2009) 181-185.

[16] T. Zhu, L. Xu, X.H. Zhang, W.B. Han, P. Hu, L. Weng, Densification, microstructure and mechanical properties of $\mathrm{ZrB}_{2}-\mathrm{SiC}_{\mathrm{w}}$ ceramic composites, J. Eur. Ceram. Soc. 29 (2009) 2893-2901.

[17] X.H. Zhang, L. Xu, S.Y. Du, J.C. Han, P. Hu, W.B. Han, Fabrication and mechanical properties of $\mathrm{ZrB}_{2}-\mathrm{SiC}_{\mathrm{w}}$ ceramic matrix composite, Mater. Lett. 62 (2008) 1058-1060.

[18] S.Y. Du, L. Xu, X.H. Zhang, P. Hu, W.B. Han, Effect of sintering temperature and holding time on the microstructure and mechanical properties of $\mathrm{ZrB}_{2}-\mathrm{SiC}_{\mathrm{w}}$ composites, Mater. Chem. Phys. 116 (2009) 76-80.

[19] P. Zhang, P. Hu, X.H. Zhang, J.C. Han, S.H. Meng, Processing and characterization of $\mathrm{ZrB}_{2}-\mathrm{SiC}_{\mathrm{w}}$ ultra-high temperature ceramics, J. Alloy. Compd. 472 (2009) 358-362.

20] X.H. Zhang, L. Xu, S.Y Du, CY Liu, J.C. Han, W.B. Han, Spark plasma sintering and hot pressing of $\mathrm{ZrB}_{2}-\mathrm{SiC}_{\mathrm{w}}$ ultra-high temperature ceramics, J. Alloy. Compd. 466 (2008) 241-245.

[21] J. Lin, Y. Huang, H.A. Zhang, Damage resistance, R-curve behavior and toughening mechanisms of $\mathrm{ZrB}_{2}$-based composites with $\mathrm{SiC}$ whiskers and $\mathrm{ZrO}_{2}$ fibers, Ceram. Int. 41 (2015) 2690-2698.

[22] X.H. Zhang, Y.M. An, J.C. Han, W.B. Han, G.D. Zhao, X.X. Jin, Graphene nanosheet reinforced $\mathrm{ZrB}_{2}-\mathrm{SiC}$ ceramic composite by thermal reduction of graphene oxide, RSC Adv. 5 (2015) 47060-47065.

[23] G.B. Yadhukulakrishnan, S. Karumuri, A. Rahman, R.P. Singh, A.K. Kalkan, S. P. Harimkar, Spark plasma sintering of graphene reinforced zirconium diboride ultra-high temperature ceramic composites, Ceram. Int. 39 (2013) 6637-6646.

[24] J.L. Zhang, H.J. Yang, G.X. Shen, P. Cheng, J.Y Zhang, S.W. Guo, Reduction of graphene oxide via L-ascorbic acid, Chem. Comm. 46 (2010) 1112-1114.

[25] Q. Zhang, C.G. Tian, A.P. Wu, T.X. Tan, L. Sun, L. Wang, H.G. Fu, A facile one-pot route for the controllable growth of small sized and well-dispersed $\mathrm{ZnO}$ particles on GO-derived graphene, J. Mater. Chem. 22 (2012) 11778-11784.

[26] F. Liu, S.Y. Song, D.F. Xue, H.G. Zhang, Folded structured graphene paper for high performance electrode materials, Adv. Mater. 24 (2012) 1089-1094.

[27] Y.X. Wang, S.L. Chou, H.K. Liu, S.X. Dou, Reduced graphene oxide with superior cycling stability and rate capability for sodium storage, Carbon 57 (2013) 202-208.

[28] M.A. Pimenta, G. Dresselhaus, M.S. Dresselhaus, L.G. Cançado, A. Jorio, R. Saito, Studying disorder in graphite-based systems by Raman spectroscopy, Phys. Chem. Chem. Phys. 9 (2007) 1276-1291.

[29] A.C. Ferrari, J.C. Meyer, V. Scardaci, C. Casiraghi, M. Lazzeri, F. Mauri, S. Piscanec, D. Jiang, K.S. Novoselov, S. Roth, A.K. Geim, Raman spectrum of graphene and graphene layers, Phys. Rev. Lett. 97 (2006) 187401.

[30] A.L. Chamberlain, W.G. Fahrenholtz, G.E. Hilmas, D.T. Ellerby, High-strength zirconium diboride-based ceramics, J. Am. Ceram. Soc. 87 (2004) 1170-1172. 